\title{
Evolution of Transgender Employment Discrimination in U.S. Courts
}

\author{
Rusty L. Juban \\ Southeastern Louisiana University \\ Andrė L. Honorèe \\ Southeastern Louisiana University
}

\begin{abstract}
The paper examines federal court cases involving transgender employment discrimination in the United States over the last five decades. It documents the evolution in verdicts and provides an examination of case characteristics related to outcomes. The findings suggest that the number and success rate of cases by transgender plaintiffs are both increasing. The outcomes of such cases were not found to be discernibly different based on geographic location and/or organizational typeloccupations of the plaintiffs. Plaintiffs were found to have more success in cases with claims of gender dysphoria and cases with certain types of alleged adverse actions from employers.
\end{abstract}

Keywords: transgender, employment discrimination, federal cases

\section{INTRODUCTION}

The history of employment discrimination against various minorities (e.g., race, ethnicity), demographic groups (e.g., sex, those over 40-years old) and other types of individuals (e.g., those with disabilities, pregnant, religious choice, etc...) in the United States (U.S.) is well documented and often noted for its pervasiveness and severity. However, in response to such forms of employment discrimination, American governmental leaders have often countered with the passage and enforcement of a myriad of equal employment opportunity (EEO) laws at the federal, state, and local levels that seek to eliminate such forms of bigotry and/or inequity in the workplace (Green, 2003).

These changes in offering EEO protection for different types of employees are often the result of society having an evolving view of what is (and is not) acceptable and the resultant push for greater acceptance of differences. Further, these changes have resulted in a workplace with greater access to jobs, the freedom of knowing that one cannot be denied benefits granted to employees from the majority, and the ability to seek restitution for harassment and retaliation.

With this tradition of evolving employment discrimination protections afforded to those who have been victimized in the workplace, today, given the level and type of mistreatment, many employees who are negatively affected due to their gender identity or expression are calling for similar protections. The National Center for Transgender Equality described workplace harassment as "a near universal experience" for transgender and gender non-conforming employees with $90 \%$ of those surveyed $(n=6,450)$ stating that they had been harassed at work or compelled to take "protective actions" (such as concealing their gender identity) in order to avoid being harassed (Grant et al., 2011). At the time of the 
survey, respondents stated to have experienced an unemployment rate at twice that of the general population (with transgender people of color responding as being unemployed at four times the national unemployment rate). Furthermore, forty-seven percent surveyed indicated having been discriminated against based on their gender identity or expression by not being hired, fired, or denied a promotion. These survey results along with the unique transgender work-related challenges such as the use of gender appropriate restrooms, employee dress codes and changes to official documents (e.g., driver's licenses and birth certificates) would suggest that many such employees who feel discriminated at work due to their gender identity/expression, would favor similar EEO protections of protected classes and legal remedies in the courts.

However, to date, no empirical research has examined federal employment discrimination cases involving plaintiffs who allege that being transgender was the basis for their being aggrieved in the workplace. This despite the fact that according to a report (using data from the Center for Disease Control's Behavioral Risk Factor Surveillance System) published by the Williams Institute, (Flores, Herman, Gates, \& Brown, 2016) that the estimated size of adults who identify as transgender has doubled in the last decade to an estimated 1.4 million people ( $0.6 \%$ of the U.S. adult population). Thus, the purpose of this paper is to address this gap in the transgender research by clarifying terminology, providing a brief legal history, and then report the findings with discussion of empirical results of federal employment discrimination cases in the United States.

\section{Terminology}

Part of the difficulties that transgender individuals face are a result of society's misunderstanding of various terms, and how gender relates to a person's sense of identity. It is important to note that while the terms are often used interchangeably, 'sex' and 'gender' are not the same. Sex is a biological term involving chromosomes and anatomy (however, there is a debate that sex is more complex than just male or female genes and body parts) (Sterling, 2018). Gender, on the other hand, has a culturally derived meaning and is experienced in different ways by individuals. Gender is not based on an individual's assigned sex, sexual orientation or even how someone dresses. Instead, gender is how a person feels on the inside. For most of society, there is a congruence between their assigned sex and their gender identity. This is referred to as cisgender. However, for transgender individuals, there is not the same certainty that their assigned sex at birth matches their gender identity. When a person feels discomfort and stress associated with one's own anatomy or other's expectations of their gender, it can lead to a condition referred to as gender dysphoria, a clinical term that equates to an individual's desire to express themselves as conforming to their gender rather than their assigned sex (American Psychiatric Association, 2019). To add to the complexity of how gender is experienced, gender identity is not a binary concept (meaning only male or female). Identity can exist across a continuum and some wish not to be labeled at all.

Gender expression on the other hand refers to the external manifestations of gender (American Psychological Association, 2019). These may be conveyed by transgender individuals through their choice of clothing, haircut, names, tone of voice, and other behaviors/body characteristics. While society defines these outward signs as masculine and feminine, it should be noted that what is considered either by society readily changes over time and varies by culture. Rather than their given sex at birth, transgender people generally seek to match their gender expression with their current gender identity.

In sum, transgender is an umbrella term to describe individuals whose gender identity and/or gender expression contrasts with what is usually associated with the sex they were designated at birth (American Psychological Association, 2019). Throughout the paper, it is this broad and inclusive definition of transgender, incorporating both individuals' gender identity and expression that will be employed.

\section{Pivotal Legal Moments}

One, if not the, most significant pieces of employment discrimination legislation in the United States is the Civil Rights Act of 1964. Specifically, Title VII of the Civil Rights Act (1964) which prohibits discrimination on the basis of race, color, religion, sex or national origin. This act, which also established the Equal Employment Opportunity Commission (EEOC) to administer and enforce civil rights in alleged 
employment discrimination cases, is the legal basis for most litigation involving employment discrimination. However, while the act was originally considered broad in reach by covering multiple forms of discrimination, the framers could not foresee the evolution of how it would later be interpreted by the subsequent judges and courts and was later updated by subsequent legislation (e.g., Civil Rights Acts of 1968, 1991; Civil Rights Restoration Act of 1987).

The early cases alleging transgender discrimination saw the courts' strict adherence to the definition of protected classes (e.g., race, age, religion, or sex) outlined in legislation (Franklin \& Chinn, 2017). There was no allowance for transgender employees to be considered a protected class because they did not fit into the court's view of sex as male or female (not gender identity). For example, in 1975, Paula Grossman, a transgender teacher, was fired from her job after a sexual reassignment surgery (Grossman v Bernards Township Bd. Of Education, 1976). The New Jersey Supreme Court rejected the appeal of the plaintiff based on the view that 'sex' discrimination, particularly with regard to transgender people, was not included in the original intent of Title VII protection. Similarly, in Ulane v. Eastern Airlines Inc. (1984), a transgender pilot was denied her Title VII (of the Civil Rights Act of 1964) sex discrimination protection by the U.S. Seventh Circuit Court of Appeals, by narrowly interpreting "sex" discrimination as discrimination "against women."

Surprisingly the case that would expand transgender employment rights did not come from an employment case with a transgender plaintiff, but instead from a senior cisgender female accountant at a large certified public accounting firm. Price Waterhouse v. Hopkins (1989) was a landmark case that changed the Supreme Court's interpretation of sex and gender as protected under Title VII of the Civil Rights Act. The plaintiff in this case was denied partnership within the firm based on stereotypes for women held by the senior managing partners. While an excellent performer, Hopkins was criticized for her personality and interpersonal skills. She was seen as "not lady like,", "macho," and "was a lady using foul language." It was the partners' negative reactions to Hopkins' non-conformity to gender roles that opened the door for greater scrutiny on not only sex discrimination, but also the treatment of stereotypes. Where previous cases had focused on the issue of 'sex' stereotyping, the court in this case ruled that discrimination based on 'gender' was also actionable.

After Price Waterhouse v Hopkins, there were numerous attempts by transgender employees to seek transgender protection under Title VII. It would take seven more years for a case that clarified the rights of transgender employees and the EEOC identified them as a protected class (Landsittle, 2010). David Schroer, a retired Army colonel with twenty-five years of service, was interviewed and offered a job at the Library of Congress as a research analyst. After accepting the position, he informed his new employer that he was diagnosed with a gender disorder and would be transitioning from male to female and would now present himself as Diane Schroer. Upon hearing of her change in identity and intention to present as a woman, the job offer to Schroer was rescinded. In response, Schroer filed suit for sex discrimination under Title VII. In Schroer v Billington, 2009, the D.C. Federal Court ruled that the employer's "refusal to hire Schroer after being advised that she planned to change her anatomical sex by undergoing sex reassignment surgery was literally discrimination 'because of ... sex." This case broke with previous rulings in transgender cases where the court based discrimination on the plaintiff's status as either male or female (at birth) and extended protection to cover transgender individuals as an authentic protected group.

After Schroer v Billington, there have been numerous attempts to clarify the best legal path for transgender employees to follow when they encounter discrimination (Franklin \& Chinn, 2017). A cursory view of general employment discrimination cases filed in the United States indicates that they commonly cite Title VII of the Civil Rights Act due to its provision of protections and its coverage on a federal level. In general, this also holds true for transgender employees who claim workplace discrimination. However, due to Title VII's omission of clear and specific language that protects gender discrimination of transgender employees, it is not a given that the basis of discrimination will be accepted or applied consistently in such cases.

Given this evolving and often disparate nature of significant court case rulings of employment discrimination of transgender plaintiffs, this study sought to be the first to examine many of characteristics and outcomes of such federal employment discrimination cases. 


\section{METHOD}

This study examined various characteristics and judicial outcomes of employment discrimination cases involving transgender employees in U.S. district and appellate courts. Federal employment discrimination cases were selected as they generally involve an individual employee or small group of individuals (plaintiffs) versus a business entity (e.g., corporation) or local, state, or federal government (defendants). Furthermore, in U.S. district/appellate courts, plaintiffs typically allege that they were discriminated (e.g., on the basis of race, sex, age, religion) against in the workplace by the defendant. For this study, the cases selected involved claims/charges against defendants by plaintiffs who alleged they were discriminated against (adversely impacted) for being transgender in the workplace.

To address the purposes of this study, the researchers employed the Nexis Uni electronic database in a query of U.S. district and appellate courts to identify all transgender employment discrimination cases. While transgender is generally a good term to use today (American Psychological Association, 2019), not everyone whose appearance/behavior is gender nonconforming will identify as a transgender person and the term(s) used to describe such individuals has and continues to change over time. Thus, in order to potentially capture all of the alleged plaintiff employment discrimination cases the authors desired, eleven different search terms were employed (see Table 1) in order to identify these cases over the last five decades. Specifically, within Nexis Uni, all federal cases were selected followed by each of the search terms. Within each of the eleven search terms, the broad term "discrimination" was first selected to focus the research aims of the study. To further focus the research, only "labor and employment law" practice areas/topics were selected. Table 1 indicates the initial cases identified by each search term throughout this process and indicates the range of years in which cases were found utilizing each term.

TABLE 1

\section{SEARCH TERMS AND RESULTANT CASES IDENTIFIED UTILIZING NEXIS UNI ELECTRONIC DATABASE}

\begin{tabular}{|l|c|c|c|c|}
\hline $\begin{array}{l}\text { Initial Search } \\
\text { Phrase }\end{array}$ & $\begin{array}{c}\text { Initial Number of } \\
\text { Cases }\end{array}$ & $\begin{array}{c}\text { Number of } \\
\text { Discrimination Cases }\end{array}$ & $\begin{array}{c}\text { Number of Labor } \\
\text { \& Employment } \\
\text { Law Cases }\end{array}$ & $\begin{array}{c}\text { Dates of Cases } \\
\text { Involving Search } \\
\text { Terms }\end{array}$ \\
\hline Transgender & 1329 & 636 & 344 & $1996-2018$ \\
\hline Transsexual & 814 & 343 & 233 & $1975-2018$ \\
\hline Transvestite & 172 & 73 & 45 & $1983-2018$ \\
\hline $\begin{array}{l}\text { Gender Non- } \\
\text { Conforming }\end{array}$ & 90 & 85 & $2004-2018$ \\
\hline Genderqueer & 5 & 3 & 20 & $2017-2018$ \\
\hline Cross-dress & 148 & 43 & 467 & $1984-2016$ \\
\hline Gender Identity & 1096 & 650 & 1 & 2017 \\
\hline Non-Binary & 31 & 2 & 15 & $2002-2005$ \\
\hline Drag Queens & 37 & 18 & 3 & $1999-2017$ \\
\hline Third Gender & 5 & 31 & $\mathbf{1 2 7 7}$ & $\mathbf{1 9 7 5 - 2 0 1 8}$ \\
\hline $\begin{array}{l}\text { Gender } \\
\text { Expression }\end{array}$ & 101 & $\mathbf{1 9 4 7}$ & & \\
\hline Total & $\mathbf{3 8 2 8}$ & & & $2006-2018$ \\
\hline
\end{tabular}


From this initial set of 1,277 cases, both researchers together examined each case and removed from the data set any cases that did not involve employment discrimination (e.g., inmates, use of school bathrooms), were duplications of other cases, or cases that did not involve transgender plaintiffs alleging their gender identity/expression as a basis for their employment discrimination claim. The researchers further limited their analysis to cases in which the defendant presented to the court a motion for summary disposition of the plaintiff's lawsuit, and the judge(s) ruled on that motion. This was done because such cases indicate a decision by the judge in favor of one party over the other and because cases decided by jury verdicts are not reported in any national legal database (e.g., Westlaw, Nexis Uni).

The determination and assignment of each cases' outcome was mutually agreed upon by both authors and involved a sophisticated analysis of judges' rulings. In these resultant transgender plaintiff cases, judges often were required to make additional/multiple rulings on a variety of other issues that were beyond the scope of this study (e.g., administrative rulings, rulings on other employment related claims such as race, or age). Thus in keeping with the purpose of the study, the authors coding of case outcomes only reflected judges' rulings involving the plaintiff's claim employment discrimination as a result of being transgender.

The outcomes of these selected transgender claim cases were then assigned one of two values. Cases were coded as "defendant wins" where the defendant's motion was granted and the case was dismissed with prejudice. In all other cases, either where the defendant's motion was denied or where the motion was granted in part (the alleged discrimination resulting from being transgender) and denied in part, the value "plaintiff wins" was assigned. These cases were coded as verdicts favoring the transgender plaintiff primarily for two reasons. First, cases with verdicts involving a partial denial of summary judgement to the defendant allows the plaintiff to proceed to trial and present their case before a jury. Second, by surviving summary judgement, the plaintiff is given significant bargaining power with regard to the defendant, which often leads to a settlement of the plaintiff's claims.

Despite the use of eleven search terms, initially identifying thousands of potentially relevant transgender employment discrimination cases across five decades, the vast majority of these cases were found not to involve transgender plaintiffs versus their employers. Instead, the transgender terms were most often used in judge's arguments in cases involving homosexual plaintiffs or others not relevant to the purposes of this study. The resulting data set included 97 federal employment discrimination cases.

\section{RESULTS}

Frequency analyses and cross tabulations were conducted on the data set to provide a general summary of characteristics related to the findings of federal transgender employment discrimination cases. 
FIGURE 1

STACKED BAR COUNT OF YEAR FILED BY VERDICT

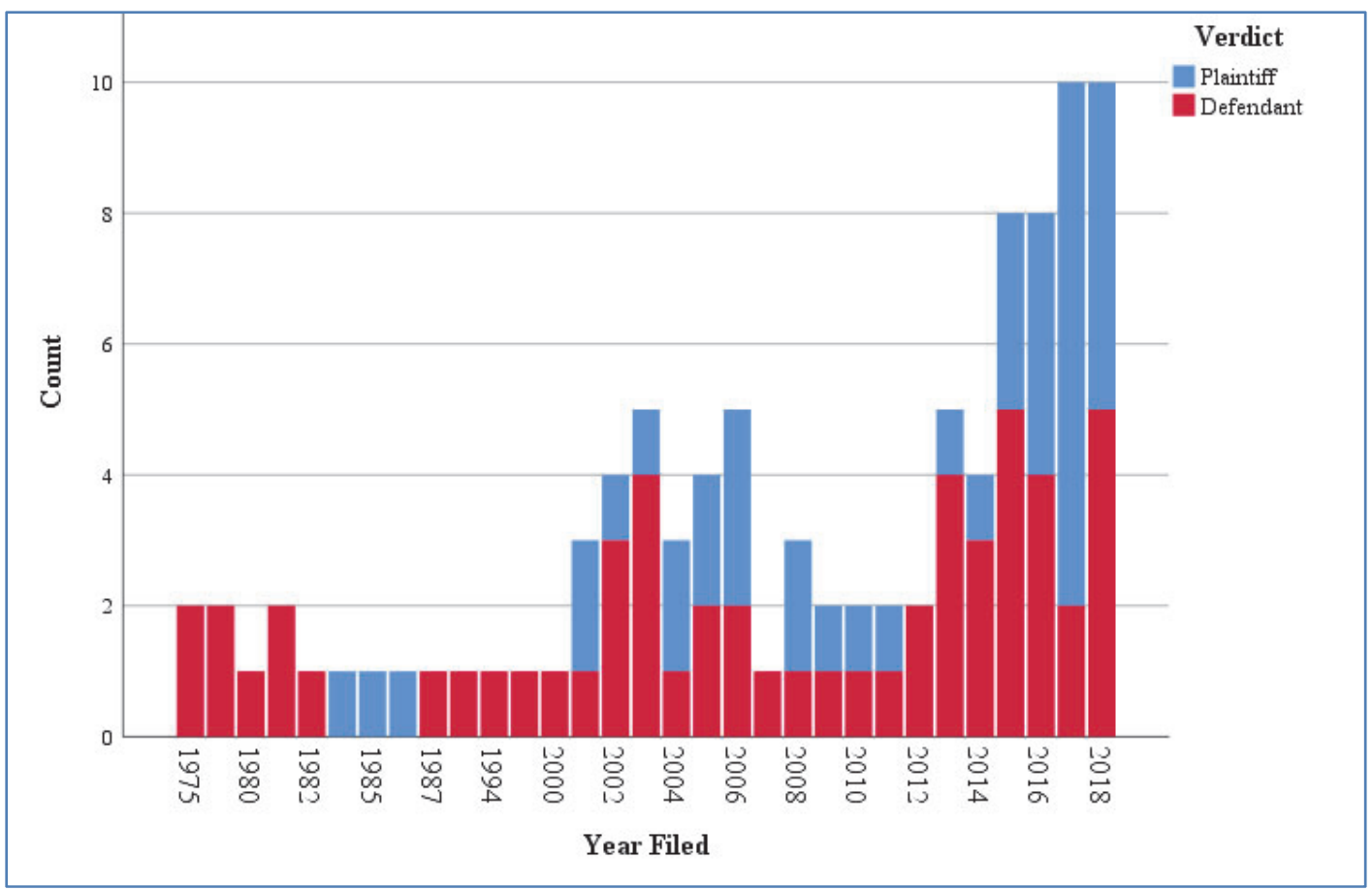

\section{Outcome/Number of Cases by Year Filed}

The number of transgender discrimination cases at the federal level has increased considerably in the last two decades. Specifically, the most cases filed in any one year was ten, which occurred in both 2017 and 2018. Further, when examining the pattern of verdicts, it is evident that more plaintiffs have won recently. From 1975 to 1985, (the first ten years of transgender court cases), there were a total of 10 cases -2 of which were decided in favor of the plaintiff. From 2008-2018 (the part of the year collected), there were 55 cases -25 of which were decided in favor of the plaintiff. That is an improvement of wins for the plaintiffs from $20 \%$ to $45.5 \%$ respectively.

Across all 97 cases identified as transgender employment discrimination (from 1975 to 2018), 42.2\% found for the plaintiff, $57.7 \%$ for the defendant and $1 \%$ other (and unknown). 
TABLE 2

CROSSTAB: CIRCUIT OF CASE BY VERDICT

\begin{tabular}{lc|c|c}
\hline & \multicolumn{2}{c|}{ Verdict } & \multirow{2}{*}{ Total } \\
\hline $1^{\text {st }}$ Circuit & Plaintiff & Defendant & \\
\hline $2^{\text {nd }}$ Circuit & 0 & 1 & 1 \\
\hline $3^{\text {rd }}$ Circuit & 4 & 6 & 10 \\
\hline $4^{\text {th }}$ Circuit & 3 & 6 & 9 \\
\hline $5^{\text {th }}$ Circuit & 5 & 8 & 13 \\
\hline $6^{\text {th }}$ Circuit & 2 & 5 & 7 \\
\hline $7^{\text {th }}$ Circuit & 9 & 8 & 17 \\
\hline $8^{\text {th }}$ Circuit & 4 & 3 & 7 \\
\hline $9^{\text {th }}$ Circuit & 2 & 5 & 7 \\
\hline $10^{\text {th }}$ Circuit & 2 & 7 & 9 \\
\hline $11^{\text {th }}$ Circuit & 3 & 4 & 7 \\
\hline $12^{\text {th }}$ Circuit & 4 & 3 & 7 \\
\hline Total & 3 & 0 & 3 \\
\hline
\end{tabular}

\section{Outcomes by Circuit Courts}

There are twelve regional circuits (comprised of 94 U.S. judicial districts) that serve as divisions under the U.S. Federal Courts system. Dependent upon which state the alleged discrimination occurred, plaintiffs file their claims in a district court in one of these disparate twelve circuits. The states in these circuits are dissimilar in many ways including demographic composition and population size.

From this data set, two circuits were found to have the most cases. First, the $6^{\text {th }}$ Circuit (comprised of Kentucky, Michigan, Ohio, and Tennessee) was found to have 17 cases followed by the $4^{\text {th }}$ Circuit (comprised of Maryland, North Carolina, South Carolina, Virginia, and West Virginia) with 13. These represent the Midwestern and southeastern coastal states respectively. The primarily northeastern/New England $1^{\text {st }}$ Circuit (comprised of Maine, Massachusetts, New Hampshire, Puerto Rico, and Rhode Island) was found to have the least amount with only one case identified.

\section{Outcomes in District by Outcomes in Appellate Courts}

The Thirteenth Circuit is the Federal Judicial Circuit that has nationwide jurisdiction over cases involving appeals. Of the total 97 cases identified, 78 were tried for the first time in one of the twelve district courts $(80.4 \%)$, while 19 were cases that dealt with appeals to the Federal Judicial Circuit $(19.5 \%)$

There were substantial differences found in the verdicts at either level. At the district level, plaintiffs were found to be successful in almost $45 \%$ of the cases while in the appeals courts, verdicts for the plaintiffs were only found to be successful in about $32 \%$ of the cases.

\section{Outcomes by Organizational Type}

With the small number of transgender discrimination cases uncovered, the study limited the categorization of employment organization type to either public (e.g., federal, state, local government) or private (non-governmental businesses/organizations).

The study identified more private $(61.9 \%)$ than public $(38.1 \%)$ cases involving alleged transgender employment discrimination. The results of the cross tabulation of organization type and verdict seems to indicate that the type of organization ( $40 \%$ verdict for plaintiffs in private organizations vs. $46 \%$ in public organizations) did not differ with regard to verdict between private and public organizations. Nor did either organization type differ dramatically from the overall verdict for plaintiff success rate of $42.2 \%$. 


\section{Outcomes by Occupation of Plaintiffs}

The study characterized plaintiffs as either blue or white-collar workers (based on the cases reporting of their job titles and duties). From the cases, $40.2 \%$ were classified as blue collar, $53.6 \%$ as white collar, and the remaining $6.2 \%$ as unknown (as the occupation of the plaintiff was not mentioned in the case). Results from cross tabulation show that blue-collar plaintiffs $(35.9 \%)$ were less likely to win than whitecollar (44.2\%) plaintiffs.

TABLE 3

CROSSTAB: EXPRESSED GENDER OF PLAINTIFF BY VERDICT

\begin{tabular}{lc|c|c}
\hline & \multicolumn{2}{c}{ Verdict } & Total \\
& Plaintiff & Defendant & \\
\hline Male & 6 & 6 & 12 \\
\hline Female & 31 & 48 & 79 \\
\hline Non-Binary & 3 & 2 & 5 \\
\hline Total & 40 & 56 & 96 \\
\hline
\end{tabular}

\section{Outcomes by Expressed Gender of Plaintiff}

In $82.3 \%$ of the cases, the plaintiffs identified/expressed their gender as being female. Only $12.5 \%$ of cases involved plaintiffs who identified/expressed themselves as male, 5.2\% identified/expressed themselves as non-binary (a relatively new classification), and 1\% could not be determined from the case supporting documents. The cross tabulation results indicated that the expressed gender of the client did differ with regard to verdict success. Specifically, verdicts for male plaintiffs $(50 \%)$ were higher than that of female plaintiffs $(39.2 \%)$ but lower than that of verdicts for plaintiffs in non-binary cases $(60 \%)$.

TABLE 4

CROSSTAB: DISORDER/DYSPHORIA BY VERDICT

\begin{tabular}{lc|c|c}
\hline & \multicolumn{2}{c|}{ Verdict } & \\
& Plaintiff & Defendant & Total \\
\hline No Gender Disorder/Dysphoria & 20 & 39 & 59 \\
\hline Gender Disorder/Dysphoria & 20 & 17 & 37 \\
\hline Total & 40 & 56 & 96 \\
\hline
\end{tabular}

\section{Outcome by Gender Disorder/Dysphoria}

Over the decades of data collected for this study, the terminology employed by plaintiffs in such employment discrimination cases evolved from that of claiming a gender disorder to that of claiming to have gender dysphoria. Collapsing these terms for this study identified $61.5 \%$ of cases where plaintiffs made no such claims and $38.5 \%$ claiming to either have a gender disorder or gender dysphoria.

These differences in the plaintiffs' claims were noteworthy as plaintiffs who made such claims were roughly $20 \%$ more likely to be successful than those who did not (54\% to $34 \%$ respectively). 
TABLE 5

CROSSTAB: ADVERSE IMPACT BY VERDICT

\begin{tabular}{lc|c|c|c|c|c}
\hline & \multicolumn{2}{c}{ Plaintiff } & \multicolumn{2}{c}{ Defendant } & \multicolumn{2}{c}{ Total } \\
& $\mathrm{N}$ & Percent & $\mathrm{N}$ & Percent & $\mathrm{N}$ & Percent \\
\hline Fired & 20 & $33.9 \%$ & 39 & $66.1 \%$ & 59 & $60.8 \%$ \\
\hline Not Hired & 15 & $62.5 \%$ & 9 & $37.5 \%$ & 24 & $24.7 \%$ \\
\hline Harassment & 8 & $47.1 \%$ & 9 & $52.9 \%$ & 17 & $17.5 \%$ \\
\hline Retaliation & 7 & $58.3 \%$ & 5 & $41.6 \%$ & 12 & $12.4 \%$ \\
\hline Denied Benefits & 5 & $50.0 \%$ & 5 & $50.0 \%$ & 10 & $10.3 \%$ \\
\hline
\end{tabular}

Outcome by Type of Adverse Action

The study identified a variety of different claims of adverse action (how plaintiffs were negatively impacted) by defendants because of alleged transgender employment discrimination. As would be expected, in some cases plaintiffs only made one claim, but in many of the cases, there were multiple claims of adverse action (e.g., being fired, not hired, etc...) by the organization.

The most common claim was firing, followed by not being hired, harassment, retaliation and being denied employment benefits. Of the adverse actions, discrimination in hiring had the highest percentages of win for the plaintiff at $62.5 \%$, while being fired had the lowest level of success at only $34 \%$ of such adverse actions claims favoring plaintiffs.

\section{DISCUSSION}

Historically, employees' transgender expression has been stigmatized at work and it is only recently through actions by the EEOC and case law that this group has been afforded the legal protection of other protected classes (though no federal law specifically covers gender identity discrimination) (Dietert, 2009). In this study, the authors delved into the last five decades of transgender discrimination cases brought before federal U.S. courts to better understand the status of transgender litigation outcomes.

Given past survey results (Grant et al., 2011) and the attention transgender issues have received, the resultant sample of 97 federal employment discrimination cases was unexpected. For as a group, in workplaces in which their gender expression is not readily accepted (e.g., cross-dressing, gender reassignment surgery), it would seem to have generated more claims of adverse action from their employers. However, perhaps the recent increase in the number of cases found in this sample (roughly since the turn of the century) and the increase in number of plaintiff victories, reflects changing societal views and ensuing court opinions. Similar to how the rights of other minorities/groups have evolved, employment protection is granted through a process of refining terms and increased understanding. Given the recent trends found in this data, in the future, one would expect to see more cases filed and decided in favor of transgender plaintiffs.

The study examined federal court cases which are organized into thirteen districts (one of which being the court of appeals). The number of cases found in each district was surprising, as one would have expected a greater number of cases in areas with larger populations (i.e. the $9^{\text {th }}$ circuit - which includes four states with the nation's highest transgender populations). The disparity found in the plaintiff success rate between the district and appellate courts would be an interesting topic for future research.

Results from this study show there are roughly an equal number of transgender employment discrimination cases being brought from both blue and white-collar workers and in both public and private companies. As future litigation is filed, trends may evolve in these areas, but as for now this study found no evidence that would indicate transgender discrimination cases are more prominently found in particular occupations or at certain types of companies, nor any discernable differences in the outcomes of such cases. 
Findings indicate that most transgender employment discrimination cases are brought by transgender females. However, several cases also involved a plaintiff identifying as non-binary, a finding one would expect to increase in the future as this term comes into greater use. In addition, a significant number of cases involved plaintiffs who had identified as having a gender disorder/gender dysphoria. The study's findings suggest that plaintiffs who identified as having a gender disorder (or dysphoria) were more likely to win their case. In effect, these plaintiffs imply that their behavior is not the result of a conscious choice to dress or act differently, but instead the result of dealing with the condition of living with gender inappropriateness (Bradley \& Zucker, 2001). It was interesting to note that in none of the cases examined did the plaintiff pursue accommodation under the Americans with Disabilities Act.

With varying levels of success in case outcomes, this study details transgender plaintiff employment discrimination claims resulting from a variety of alleged adverse actions (e.g., not hired, fired, etc...) by employers. For employees, their employers, and the legal teams that represent each, it would be beneficial to understand how the type of claim in such cases may affect a party's chance of success. In examining case summaries, companies that had fired transgender employees were more successful in their case when they argued on contextual grounds, i.e. poor performance or failure to follow established policies. Transgender applicants, on the other hand, were more successful when pre-contextual arguments such as discrimination in hiring practices were claimed.

\section{CONCLUSION}

Previously research has not empirically studied actual cases involving employment discrimination of transgender people and society has instead relied upon surveys to indicate the gravity of the issue in the United States. Perhaps this initial empirical examination of the federal court cases of transgender plaintiffs will provide some insight into factors related to who wins/loses these types of cases; and will serve as a guide to potential plaintiffs in their decision on if or what to claim in a transgender employment discrimination suit.

Surveys from the last several years show the transgender population is growing (Meerwijk \& Sevelius, 2017). Future growth is predicted to come from teens and young adults who are more open to expressing their transgender status due to changing cultural norms. While this may contribute to more transgender employment discrimination cases in the future, the authors note that two other factors may point to an increase in litigation. First, recent surveys show that $30 \%$ of transgender employees perceive discrimination at work in the form of termination, physical or verbal assault (James et al., 2016). As more plaintiffs are successful, this may encourage transgender employees who experience discrimination to come forward (Gresko, 2016). Second, there is a trend toward more employees identifying as transgender. This and survey findings which show more acceptance of differing forms of gender identify and expression around the world (Flores, Herman, Gates, \& Brown, 2016) may lead to new laws prohibiting discrimination against such individuals in the workplace. 


\section{REFERENCES}

American Psychological Association. (2019). Transgender people, gender identity and gender expression. Retrieved from https://www.apa.org/topics/lgbt/transgender

American Psychiatric Association. (2019). What is gender dysphoria? Retrieved from https://www.psychiatry.org/patients-families/gender-dysphoria/what-is-gender-dysphoria

Bradley, S., \& Zucker, K. (2001). Gender identity disorders. International Encyclopedia of the Social \& Behavioral Sciences, 6011-6016.

Dietert, D. (2009). Gender identity issues and workplace discrimination: The transgender experience. Journal of Workplace Rights, 14(1), 121-140.

Flores, A., Herman, J., Gates, G., \& Brown, T. (2016). How many adults identify as transgender in the United States? [online] The Williams Institute. Retrieved from https://williamsinstitute.law.ucla.edu/research/how-many-adults-identify-as-transgender-in-theunited-states/

Franklin, K., \& Chinn, S. (2017). Transsexual, transgender, trans: Reading judicial nomenclature in Title VII cases. Berkeley Journal of Gender, Law \& Justice, Summer, 32, 1-37.

Grant, J., Mottet, L., Tanis, J., Harrison, J., Herman, J., \& Keisling, M. (2011). Injustice at every turn: a report of the national transgender discrimination survey. Washington, DC: National Center for Transgender Equality and National Gay and Lesbian Task Force.

Green, T. (2003). Discrimination in workplace dynamics: Toward a structural account of disparate treatment history. Harvard Civil Rights-Civil Liberties Law Review, Winter, 38(1), 91-157.

Grossman v. Bernards Township Bd. of Education. (1976). LEXIS 3194 (Supreme Court of the United States) 11, 214.

James, S., Herman, J., Rankin, S., Keisling, M., Mottet, L., \& Anafi, M. (2016). The Report of the 2015 U.S. transgender survey. Washington, DC: National Center for Transgender Equality.

Landsittle, S. (2010). Strange bedfellows? Sex, religion, and transgender identity under Title VII. Northwestern University Law Review, 104 (3), 1147-1176.

Meerwijk, E., \& Sevelius, J. (2017). Transgender population size in the United States: a meta-regression of population-based probability samples. American Journal of Public Health, 107(2), Retrieved from https://www.ncbi.nlm.nih.gov/pmc/articles/PMC5227946/

Price Waterhouse v. Hopkins. (1989). LEXIS 2230 (Supreme Court of the United States), 38,936.

Schroer v. Billington. (2009). LEXIS 43903 (United States Court for the District of Columbia), 594.

Sterling, A. (2018, May 25). Why Sex Is Not Binary the Complexity Is more than cultural. It's biological, too. The New York Times. Retrieved from https://www.nytimes.com/2018/10/25/opinion/sex-biology-binary.html

Ulane v. Eastern Airlines Inc. (1984). LEXIS 19095 (United States Court of Appeals for the Seventh Circuit), 34,675. 